\title{
Experimental Infectious Arteritis and Ulcers of the Gastric Mucosa
}

\author{
G U N NAR NORLIN \\ Chemistry Department II, Karolinska Institutet and Chemistry Department, \\ Statens Bakteriologiska Laboratorium, Stockholm, Sweden
}

\begin{abstract}
Rabbits were injected repeatedly with $\beta$-hemolytic streptococci. Besides lesions of other organs superficial ulcers were observed in the gastric mucosa of the animals.

As the arteries in the submucosa showed degenerative and proliferative inflammation the cause of the lesions was likely to be insufficient blood supply.
\end{abstract}

During experimental work on rheumatic diseases Norlin ${ }^{1}$ observed black spots on the inner surface of the stomach wall. These spots were examined histologically.

\section{MATERIAL AND METHODS}

Experimental procedure. Rabbits were divided into three groups. Group 1 contained 10 animals, which were injected intravenously first with heat killed $\beta$-hemolytic streptococci for three weeks. Then living streptococci were injected for four months. The injections were given with intervals of 3 to 6 days. The doses were always $2 \mathrm{ml}$ of a 20 hours' streptococcal culture grown on Todd-Hewitt ${ }^{2}$ broth. The strain used was the type 2 strain Rockefeller T-2/44/RB4. By mixing avirulent and virulent mutants of the strain the infection was so arranged that the rabbits got bacteria of continuously rising average virulence. The food in this group was hay, oats and Swedish turnips.

Group 2 consisted of 26 rabbits which were given $175 \mathrm{ml}$ of a mixture of equal parts of oats and rabbit pellets per day. To this food $0.5 \mathrm{~g}$ cholesterol and $5 \mathrm{~g}$ margarine was added to the daily ration.

Group 3 included 16 rabbits and they got the same "atherogenic diet" as those of group 2 and also streptococcal infections after the scheme described for group 1.

Histological technique. Necropsies were performed as soon after death as possible. The tissues were fixed in $10 \%$ formalin solution, and sections cut from paraffin blocks were stained by Weigert's hematoxylin and eosin and by van Gieson's method.

\section{RESULTS}

In the respective groups 2,2 , and 6 rabbits had ulcers in the gastric mucosa. This makes only $19 \%(10 / 52)$ on the whole material.

As a control there were used: 4 normal rabbits, 10 rabbits injected for 3 weeks with $E$. coli, 12 infected intracutaneously with vaccinia, 7 immunized 


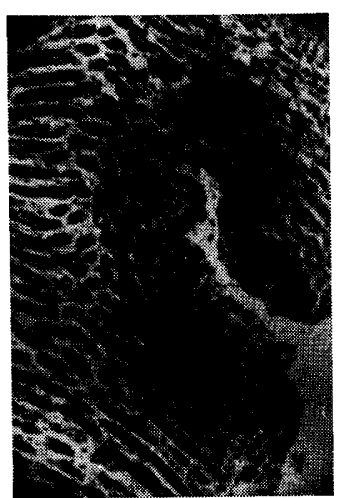

Fig. 1. Rabbit 183. Ulcer in gastric mucosa with infiltrated and necrotic margins.

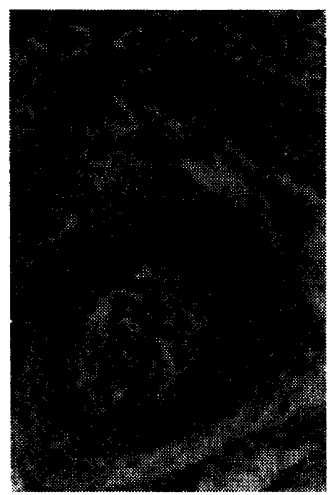

Fig. 3. Rabbit 206. Obliterating endarteritis in the bottom of a shallow ulcer.

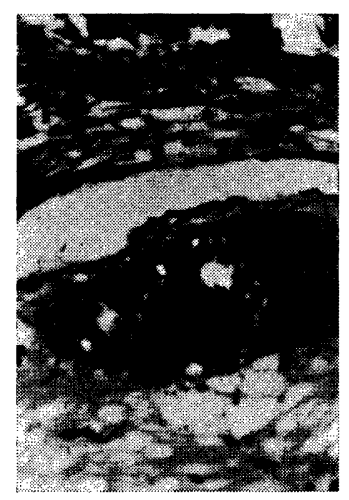

Fig. 2. Rabbit 183. Obliterating arteritis in the submucosa beneath an ulcer.



Fig. 4. Rabbit 218. Degenerated artery with "lipoid cells" beneath a large shallow ulcer.

with fungi (Epidermophyton floccosum, Keratomyces ajellii, Trichophyton equinum, Trichophyton Schoenleini or Tricophyton butonrougei) for 6 weeks and 7 others with the same fungal strains during 8-13 months. Of these 40 animals 5 had suspected superficial dark spots in the gastric mucosa, four of which were hardly visible and without microscopical lesions. Only one had a $1 \mathrm{~mm}$ greyish erosion that was seen in the microscope as a slight defect in the most superficial layer of the mucosa.

In the animals suffering from the sequelae of an infection or of atherogenic diet or both there were distinct ulcers $1-6 \mathrm{~mm}$ in diameter with more or less severe hemorrage, granulations or fibrous tissue and degeneration or necrosis of the cells of the mucosal glands. In no case a chronic ulcus proceeding through the lamina muscularis mucosae was seen. 
In group 1 both ulcers had sharp margins and necrosis and hemorrage (Fig. 1) was distinctly separated from undamaged tissue. The arteries beneath the ulcers were the seats of obliterating endarteritis (Fig. 2).

In the two latter groups of rabbits where atherogenic diet was given the mucosal ulcers were shallow and with less distinct limits between unaffected and damaged tissue. When the ulceration went down to the bottom of the glandular layer the sloping edge surrounded a digested center that was several millimeters in diameter. Whether streptococci were given or not the supplying arteries were swollen and contained abundant "lipoid cells" (Figs. 3 and 4).

Further work is needed to find out if there is any real difference between the morphology of the ulcers in the different groups.

\section{DISCUSSION}

Experimental peptic ulcers have been produced by surgical operations as in the Shay rat, where the pylorus was closed or in the Mann-Williamson dog where the pylorus was sutured to the jejunum and the duodenum to the ilium. Later investigators ${ }^{5}$ definitely ascribe these mostly marginal ulcers to impaired blood supply of the sutured areas.

Excessive doses of histamine ${ }^{6}$ also give rise to gastric ulcers but as the amounts of histamine were far beyond what can be reached physiologically ${ }^{7,8}$ these experiments prove the importance of peptic digestion but have only partial interest for the etiology of ulcers.

A considerable experience definitely points at nervous influence and stress as important ulcerogenic factors ${ }^{9}$. The experimental "restraint ulcers" in animals enclosed in narrow tubes or boxes are, although definitely unphysiological, most likely explained as being caused by stress.

The stress reaction seems to be effected via hypothalamus by ACTH and adrenal cortex hormones which increase the gastric secretion and may impair the circulation ${ }^{10}$.

It is quite instructive to read the classic text book by Boyd ${ }^{11}$ where it is suggested that the common cause of peptic ulcer might be a hematogenous infection of the stomach wall and if the ulcer healed the patient might become reinfected and a fresh ulcer would form.

Several papers read at the 2nd World Congress for Gastroenterology last year accentuate the importance of vascular lesions for the origin of peptic ulcer. Especially Hoffman ${ }^{12}$ definitely states that peptic ulcer was the result of a primary infarction.

Other recent papers ${ }^{13,14}$ also point at the vascular factors as the most important cause for the rise and chronicity of gastric ulcers. De La Fuente-Chaas et al. ${ }^{15}$ were able to show by perfusion with india ink that there were occluded blood vessels and a zone of intense ischemia in peptic ulcer. These results are in good agreement with the experimental findings of this paper.

Jahiel et al. ${ }^{16}$ realizing the infectious and vascular components of the ulcerogenic process found it likely that hypersensitivity of the Arthus type could be a possible reaction mechanism. They studied their hypothesis experimentally and sensitized rabbits with horse serum directly into the stomach wall. After $1 \frac{1}{2}-9$ weeks an intravenous "shocking" injection of horse serum gave $50 \%$ ventricular 
damages from small infiltrates and erosions to necroses and bleeding ulcers.

Several authors ${ }^{17,18}$ have observed Arthus reactions and ulcers in the stomach after general active or passive sensitization.

Norlin $^{19}$ has tried to explain the rheumatic lesions, including the arteritis, as caused by antigen-antibody complexes in antigen excess acting on an immunologically paralyzed host. This explanation is also valid for peptic ulcer as a result of a focal arteritis.

Acknowledgement. This work was supported by grants from Svenska Nationalföreningen mot Hjärt- och Lungsjukdomar and Stiftelsen Therese och Johan Anderssons minne.

\section{REFERENCES}

1. Norlin, G. Acta Rheumatol. Scand. 8 (1962) 297.

2. Todd, E. W. and Hewitt, L. F. J. Pathol. and Bacteriol. 35 (1932) 973.

3. Shay, H., Komarov, S. A., Fels, S. S., Meranze, D., Gruenstein, M. and Siplet, H. Gastroenterology 5 (1954) 43.

4. Mann, F. C. and Williamson, C. S. Annal. Surg. 77 (1923) 409.

5. Kuroyanagi, Y., Chiles, Th. and Necheles, H. Am. J. Gastroenterol. 38 (1962) 567.

6. Schmid, J. Wien. klin. Wochenschr. 1951377.

7. Levin, E., Kisner, J. B. and Palmer, W. L. Gastroenterology 12 (1949) 561.

8. Ihre, B. R. Boller, Der Magen und seine Krankheiten, Urban und Schwarzenberg, Wien und Insbruck 1954, p. 25.

9. Woldman, E. E. J. Am. Med. Assoc. 149 (1952) 984.

10. Gray, S. J., Ramsey, C., Reifenstein, R. W. and Benson Jr., J. A. Gastroenterology 25 (1953) 156.

11. Boyd, W. A Text Book of Pathology, Lea and Febiger, Philadelphia 1938, p. 526.

12. Hoffman, W. Münch. Med. Wochenschr. 104 (1962) 1679.

13. Polet, F., Conte-Marti, M., Conte, M. and Lambling, A. Arch. Maladies Appareil Digest. 50 (1961) 1038.

14. Modena, H. G. Gastroenterology 41 (1961) 174.

15. De La Fuente-Chaas, A. and Puente Dominguez, A. Intern. Abstr. Surg. 104 (1957) 354.

16. Jahiel, R., Jahiel, R. and Krakauer, J. Proc Soc. Exper. Biol. and Med. 79 (1952) 54.

17. Shapiro, P. F. and Ivy, A. C. Arch. Int. Med. 38 (1926) 237.

18. de Gara, P. F. and Angevine, P. M. J. Exper. Med. 78 (1943) 135.

19. Norlin, G. Acta Rheumatol. Scand. 8 (1962 141.

Received April 1, 1963. 